\title{
MEDIÇÃO EM CONFLITOS DE SAÚDE: CONTRIBUIÇÃO DA MEDICINA BASEADA EM EVIDÊNCIAS
}

\section{Angélica Carlini*}

\section{RESUMO}

O trabalho propõe a utilização da ferramenta da medicina baseada em evidências para ser aplicada em núcleos de mediação de conflitos de saúde, especificamente para casos de doenças raras ou de pedidos de medicamentos de alto custo, para aferir possibilidades e, eventual prática de cuidados paliativos. O objetivo é racionalizar a utilização de recursos dos setores de saúde público e privados, como garantia de efetividade de aplicação de direitos.

Palavras-Chave - Saúde. Alto Custo. Medicina Baseada em Evidência.

\section{MEASUREMENT IN HEALTH CONFLICTS: CONTRIBUTION OF MEDICINE BASED ON EVIDENCE}

\begin{abstract}
The paper proposes the use of the evidence - based medicine tool to be applied in health conflict mediation centers, specifically for cases of rare diseases or requests for high - cost medication, to assess possibilities and possible practice of care palliative The objective is to rationalize the use of resources from the public and private health sectors, as a guarantee of effective application of rights.
\end{abstract}

Keywords - Health. High Cost. Evidence-Based Medicine.

1. Introdução

Os sistemas de saúde público e suplementar enfrentam no Brasil, há pelo menos duas décadas, o desafio de utilizar os recursos econômicos de forma racional e equilibrada para fazer frente aos valores decorrentes de tratamentos e medicamentos de alto custo quase sempre destinados às doenças de maior complexidade.

As situações específicas de medicamentos e tratamento de alto custo não são os casos em maior número na justiça se comparados com a quantidade de situações concretas judicializadas na área da saúde, porém, os valores econômicos para custeio dos tratamentos e medicamentos são tão expressivos que podem comprometer em um só momento, os

\footnotetext{
* Doutora em Direito Político e Econômico. Doutora em Educação. Mestre em Direito Civil. Mestre em História Contemporânea. Pós Doutorado em Direito Civil pela PUC do Rio Grande do Sul. Graduada em Direito. Coordenadora do projeto de Pós Graduação em Direito da Universidade Metropolitana de Santos - UNIMES e professora do PPG em Administração da Universidade Paulista - UNIP. Contato - angelicacarlini@ uol.com.br. Endereço - Rua Amália Della Coleta, 701 - casa 32 - Campinas/SP.
} 
orçamentos anuais dos entes públicos e privados. O Sistema Único de Saúde - SUS gasta algo em torno de R $\$$ 7,1 bilhões por ano no custeio de medicamentos de alto custo. ${ }^{\dagger}$

A recomendação para a utilização do tratamento ou do medicamento de alto custo é realizada por um médico que, raramente, tem responsabilidade sobre a obtenção dos recursos necessários para o custeio. Na área da saúde pública e da saúde privada o médico que assiste o paciente não tem nenhuma limitação de prescrição até porque, sua liberdade de exercício profissional se encontra garantida pelo Código de Ética Médica. Ninguém pode restringir ao médico a prescrição de utilização de um tratamento ou de um medicamento, sob pena de transgredir determinação expressa da legislação que regula a atividade médica no Brasil.

Da mesma forma, não há norma legal ou infra legal que obrigue o paciente a cessar suas tentativas de sobreviver à moléstia que o acomete em razão dos altos custos do tratamento ou do medicamento que será utilizado.

Medicina baseada em evidências é um conjunto instrumental que permite aos médicos avaliar evidências de acurácia de tratamentos e de medicamentos a partir de estudos científicos, produzidos por laboratórios e institutos de pesquisa de comprovada qualidade e reconhecimento, de forma a identificar qual o percentual de chance de êxito em casos de maior complexidade ou raridade da doença e, que são aqueles que não podem ser tratados apenas a partir da experiência clínica do médico, até porque não ocorrem em quantidade tão expressiva que permita um volume de dados e conclusões empíricas suficiente para tomada de decisões.

O que se investiga neste trabalho é em que medida a utilização do recurso técnico de medicina baseada em evidência poderá contribuir para demonstrar ao paciente e ao seu próprio médico que, os recursos que serão utilizados para o tratamento e/ou medicamento poderão não resultar em melhora ou cura do paciente, ou até, agravar esse estado de saúde, ou, ainda, prejudicar sua qualidade de vida durante o período de sobrevida que lhe será viabilizado. Os dados objetivos obtidos pela medicina baseada em evidências poderão demonstrar a viabilidade de êxito do tratamento e/ou medicamento de alto custo ou, a inviabilidade do êxito ou, ainda, a inviabilidade de melhoria estado de saúde e da qualidade de vida do paciente. Nesse caso, a conduta recomendada poderá ser a introdução de cuidados paliativos, que acompanhem o paciente pelo período necessário.

\footnotetext{
${ }^{\dagger}$ Disponível em http://www.bbc.com/portuguese/brasil-41007650. Acesso em 20 de março de 2018.
} 
Essa delicada tarefa de recomendar ao paciente, ao seu médico e a sua família a opção por cuidados paliativos quando a medicina não tem mais nada a oferecer, pode ser realizada nos núcleos de solução de conflitos com trabalho de equipe multidisciplinar, mediando o conflito entre o desejo de continuar tentando tratamentos e/ou medicamentos que possam garantir a melhora no estado de saúde e a realidade comprovada cientificamente, de que essa possibilidade é muito reduzida.

O que se pretende demonstrar é que a solução de conflitos em área de saúde pública ou privada, que provoca recorrentes pedidos junto ao poder judiciário, poder ser solucionada em casos específicos de tratamentos e/ou medicamentos de alto custo com dados objetivos obtidos com técnicas de medicina baseada em evidências, que possam contribuir para definir se o uso dos recursos é viável ou não, sempre tendo por objetivo a qualidade de vida e a dignidade da pessoa humana, sem perder de vista a necessidade de uso racional dos recursos públicos e mutuais.

\section{Saúde e Acesso à Saúde: Perspectivas Constitucionais.}

A Organização Mundial de Saúde, órgão da Organização das Nações Unidas, adota o conceito de saúde como "um estado de completo bem-estar físico, mental e social e não somente a ausência de afecções e enfermidades", conforme consta da Constituição da Organização Mundial da Saúde, de 1946.

$\mathrm{Na}$ atualidade, esse conceito tem sido objeto de críticas porque não contempla a objetividade necessária para sua compreensão e correta aplicação. Se considerarmos que esse conceito é necessário para os projetos de políticas públicas, para a criação de indicadores de eficiência de ações de saúde públicas e privadas, ou, ainda, para a formação de profissionais da área de saúde, compreenderemos que a falta de objetividade cria dificuldades relevantes e não apenas retóricas.

Além disso, o estado de completo bem-estar físico, mental e social é quase impossível de ser obtido por qualquer ser humano em qualquer parte do planeta Terra neste momento histórico, marcado por inúmeros conflitos políticos, sociais e econômicos, uma época definida como de risco (BECK, U. 2017), em que impera o traço da incerteza. (MORIN, E., 1999). 
As angústias e ansiedade que grande parte dos seres humanos possuem já se constituem em alteração significativa do estado de completo bem-estar mental ou social, quase sempre com repercussões no estado físico, como observam Segre e Ferraz

(...) ainda que se recorra a conceitos "externos" de avaliação (é assim que se trabalha em Saúde Coletiva), a "perfeição" não é definível. Se se trabalhar com um referencial "objetivista", isto é, com uma avaliação do grau de perfeição, bem-estar ou felicidade de um sujeito externa a ele próprio, estar-se-á automaticamente elevando os termos perfeição, bem-estar ou felicidade a categorias que existem por si mesmas e não estão sujeitas a uma descrição dentro de um contexto que lhes empreste sentido, a partir da linguagem e da experiência íntima do sujeito. Só poder-se-ia, assim falar de bem-estar, felicidade ou perfeição para um sujeito que, dentro de suas crenças e valores, desse sentido de tal uso semântico e, portanto, o legitimasse.

Por outro lado, a angústia (com oscilações), tendo essa angústia repercussão somática maior ou menor (por exemplo, um cólon irritativo ou uma gastrite), configura situação habitual, inerente às próprias condições do ser humano. Divergir de posturas da sociedade, e até marginalizar-se ou de ser marginalizado frente a essa mesma sociedade, não obstante o sofrimento que essas situações trazem, é comum e até desejável para o homem sintonizado com o ambiente em que vive. (...)

(...)

Nessas condições, não se poderá certamente falar em "perfeito bem-estar social". Entende-se que, para fins de estatísticas de saúde, as formas de "avaliação externa" sejam necessárias; não seria exequível "qualitativar-se" esse tipo de mensuração. Essas reflexões e as que se seguirão são cabíveis para que o estudioso de ciências de saúde possa "pensar" melhor sua matéria. (SEGRE, FERRAZ, 1997, p. 328)

Alterações emocionais decorrentes de frustrações e contrariedades não são necessariamente causadoras de doenças, mas situações próprias dos diferentes processos de maturidade emocional que as pessoas enfrentam ao longo de suas vidas. Da mesma forma, é muito difícil que alguém consiga viver em condições sociais de pleno bem-estar, seja em áreas rurais ou em áreas urbanas. Mudanças climáticas, concentração de pessoas nos espaços urbanos, contaminação de mananciais, poluição do ar, entre outras circunstâncias próprias da vida contemporânea tornaram o completo bem-estar social um estado impossível de ser concretizado na sociedade contemporânea.

É necessário refletir sobre outro modelo de definição para a saúde, que leve em conta aspectos objetivos e subjetivos e, reconheça que saúde varia em razão de aspectos sociais, econômicos, históricos e culturais de cada grupo social. Boa saúde é fruto de prevenção e de tratamento, mas, ao mesmo tempo, é resultado de ampliação de conhecimento e de autoconhecimento que permita a cada pessoa viver em harmonia com suas escolhas, com sua 
forma de viver e, principalmente, com acesso a todos os meios que viabilizem a saúde, como educação, emprego ou renda, moradia, lazer, e todo o atendimento de saúde no momento e no modo necessários em caso de doença.

A dificuldade em definir saúde de forma mais objetiva repercute no momento de garantir sua concretização, porque sempre será possível argumentar que não estão atendidas todas as dimensões possíveis para a efetividade do estado de completo bem-estar físico, mental e social. E isso em boa medida também é fonte da judicialização que vivenciamos na atualidade.

O artigo 196 da Constituição Federal determina que o Estado deverá garantir a saúde mediante políticas públicas para que seja acessível a todos. Passados quase 30 anos da promulgação da Constituição Federal é fato concreto que as políticas públicas ainda não conseguiram efetivar o acesso à saúde de qualidade para toda a população, ainda que o país tenha implantado o Sistema Único de Saúde - SUS, um dos poucos sistemas em todo mundo que garante atendimento integral e universal sem contrapartida direta, porque o custeio se faz a partir dos valores de tributos.

Uma das consequências da baixa eficiência das políticas públicas de saúde foi o aumento significativo da judicialização do acesso à saúde, fenômeno visível no Brasil nos últimos anos. São milhares de demandas judiciais movidas em caráter individual e para pleitear as mais variadas necessidades e diversidade. ${ }^{*}$

As demandas acontecem no âmbito da saúde pública e suplementar e, são em volume tão expressivo que, na atualidade, há consenso na comunidade jurídica de que é preciso buscar mecanismos que possam contribuir para diminuir o número de ações, principalmente com a utilização de novas práticas entre usuários de saúde e seus prestadores de serviços.

Há consenso, também, de que as demandas judiciais são decididas por juízes quase sempre sem nenhum apoio técnico que lhes permita avaliar a recomendação médica indicada para o caso, oriunda do médico que atende o paciente e que redigiu a recomendação para um tratamento e/ou um medicamento necessário para o estado de morbidez. Como avaliar se essa recomendação é a mais adequada para o caso?

\footnotetext{
${ }^{\ddagger}$ Disponível em http://www.cnj.jus.br/files/conteudo/destaques/arquivo/2015/06/6781486daef02bc6ec8c1e491a565006.pdf. Acesso em 20 de março de 2018.
} 
Os magistrados brasileiros nem sempre dispõem de apoio técnico para tomar decisões na área da saúde. Mesmo sendo tema de alto teor técnico os magistrados são obrigados a julgar se valendo de uma segunda opinião quando a conseguem ou, adotando integralmente o parecer do médico assistente do paciente.

A Constituição Federal de 1988 adotou os direitos sociais prestacionais que concretizam o acesso à saúde, educação, assistência e previdência social, moradia, lazer entre outros, todos essenciais para plenitude do bem-estar físico, social e mental da pessoa.

Direitos sociais prestacionais devem ser realizados por políticas públicas previstas e planejadas no orçamento das diversas esferas de poder executivo, com execução garantida e fiscalizada pelos gestores desse poder, sempre com objetivo de que os recursos públicos sejam utilizados em conformidade com os princípios da administração pública, explicitados no artigo 37 da Constituição brasileira.

As políticas públicas adotadas pelos governos executivos, municipal, estadual e federal, porém, não concretizaram efetivamente o elenco de direitos sociais e, em consequência, o poder judiciário começou a ser demandado para solucionar essa defasagem.

O poder judiciário em grande parte dos casos optou por concretizar o acesso a direitos sociais prestacionais para cada cidadão que ajuizasse processo com essa finalidade, em especial para garantia da efetividade da dignidade da pessoa humana. Nesse ponto, parece ter prevalecido a tradição civilista brasileira de conhecer e julgar pleitos individuais, quase sempre de caráter patrimonial. Esse traço forte do direito brasileiro pode ter influenciado a prática da magistratura que, sem maior questionamento à necessidade de garantir os direitos sociais prestacionais por meio de políticas públicas, adotou a garantia em cada pleito individualizado sem considerar que poderia estar privilegiando os que tem acesso ao judiciário e garantem seus direitos, em detrimento daqueles que não conseguem ter acesso ao judiciário ou, que sequer sabem que podem pleitear direitos por esse meio.

A utilização do fundamento republicano da dignidade da pessoa humana para os casos concretos como argumento essencial para a efetividade do direito social prestacional no caso individualizado, parece consolidar a hipótese de que o judiciário brasileiro prosseguiu utilizando a lógica privatista, porém, com fundamentos constitucionais e para direitos sociais. 
É preciso reavaliar essa prática porque o problema não está na Constituição Federal, mas na forma como é aplicada aos casos individuais.

Christian Starck afirma que dignidade representa autodeterminação com base no valor de cada homem e também no valor próprio do próximo, a exigir, portanto, a tolerância recíproca do exercício de liberdade. Justifica por esse pressuposto que as constituições prevejam o princípio da igualdade e os limites aos direitos fundamentais, inclusive porque o exercício da dignidade exige atenção para com o próximo e para com as futuras gerações. (STARCK, C., 2013, P. 207)

O mesmo autor ao se referir a decisões do Tribunal Constitucional Federal alemão, argumenta que não basta analisar fórmulas gerais de não degradação do homem a mero objeto do poder estatal, isso é insuficiente para caracterizar verdadeira agressão à dignidade humana. A submissão do homem a leis que nem sempre levam em conta seus interesses, não pode ser tratada como agressão à dignidade. Esta só ocorre efetivamente quando, na situação concreta, há um desrespeito arbitrário da dignidade do homem, um tratamento depreciativo do homem, que deverá ser combatido ainda que por vezes, seja decorrente da própria lei.

Conclui Starck que é dever do Estado respeitar e proteger a dignidade humana, sem que isso signifique prometer tornar tudo agradável aos homens, livrando-os da dor, do medo e das consequências de suas próprias decisões. E alerta que a dignidade da pessoa humana não é um programa social, mas sim do respeito aos interesses essenciais do homem.

Não foi essa a compreensão de parte da magistratura brasileira ao julgar os pedidos individuais de acesso a tratamentos e/ou medicamentos, no âmbito público e privado. Ao contrário, nos anos mais recentes a apresentação de um relatório médico justificando sem nenhuma evidência científica a necessidade de acesso, quase sempre imediato a um tratamento ou medicamento é mais do que suficiente para que a decisão seja favorável, independente dos argumentos públicos de que não há orçamento para custear ou, dos argumentos das operadoras de saúde de que não há previsão contratual ou, ainda, previsão do tratamento e/ou medicamento no rol da Agência Nacional de Saúde Suplementar.

No âmbito das instituições privadas de saúde é de respeito à boa técnica reconhecer que as decisões judiciais dessa natureza, sem previsão no rol da ANS ou no contrato firmado entre as partes, resultam em maior utilização dos recursos econômicos do fundo mutual composto pela participação individual de cada segurado e, consequentemente, isso cria dificuldades de composição e administração desses fundos, que pode resultar em insolvência 
da operadora de saúde. Não afetam os lucros das operadoras, mas os fundos mutuais que pertencem aos usuários!

Os argumentos que defendem a prioridade da prestação de direitos sociais prestacionais por meio de políticas públicas e não de forma individualizada por sentenças judiciais, quase sempre são criticados por, aparentemente, não levarem em conta a necessidade imediata de satisfação das necessidades da pessoa que não pode esperar longo tempo por solução, sob pena de colocar sua sobrevivência em risco.

Os princípios da administração pública para serem cumpridos integralmente, exigem considerar que o uso de recursos públicos ou privados para atendimento individual coloca em risco o planejamento e o orçamento, cujos recursos foram organizados a partir da contribuição de contribuintes e para utilização em finalidades planejadas e orçadas. Quando valores não previstos em orçamentos são dispendidos para custeio de procedimentos de saúde, consequências matemáticas e financeiras são geradas em sentido contrário ao da sustentabilidade dos fundos públicos que sustentam essas operações.

No âmbito da saúde privada se dá o mesmo. O cálculo da mensalidade (contribuição) individual de cada participante do sistema privado é feita com fundamento teórico da matemática dos grandes números, ou seja, da ciência atuarial. Esses cálculos levam em conta os riscos que serão assumidos pelo sistema privado, as estatísticas de sinistralidade (materialização dos riscos) e as probabilidades de ocorrência de situações que demandem algum procedimento previsto no contrato. Com esses dados é possível calcular o fundo mutual do qual sairão os valores necessários para custear os custos dos procedimentos de saúde (hospitalização, cirurgias, procedimentos ambulatoriais, medicamentos, material especial, próteses, órteses entre outros). O fundo mutual é composto pela contribuição de cada contratante e, quando decisões judiciais obrigam ao pagamento de procedimentos e/ou medicamentos que originariamente não haviam sido previstos como probabilidade de sinistro, os recursos do fundo mutual são severamente atingidos em prejuízo dos próprios usurários/contratantes. E os fundos mutuais pertencem aos usuários e não às operadoras.

O poder judiciário não indaga a respeito da existência ou inexistência de recursos para o atendimento da situação individual levada para análise e decisão; e, também não há preocupação sobre a eventual falta de recursos para o atendimento a outros pedidos, para o 
custeio de políticas públicas ou, para a sustentabilidade dos fundos privados das operadoras de saúde.

A fundamentação das decisões pelo judiciário brasileiro não tem por característica considerar possibilidades orçamentárias ou cálculos atuariais, mesmo quando a argumentação da defesa se fundamenta exatamente nos altos custos do tratamento pleiteado e, consequentemente, no impacto desse custo para o orçamento público ou para o fundo mutual.

No direito brasileiro as decisões judiciais devem ser cumpridas de pronto, ainda que não existam recursos financeiros ou, que eles não sejam suficientes para custear aquilo que a ordem determinou. Em outras palavras, a depender do volume de recursos econômicos a serem gastos para cumprimento de uma ordem judicial, todos os demais contribuintes ou contratantes de seguros privados poderão ficar sem recursos para custear suas necessidades mais usuais, como de resto tem ocorrido com indesejável frequência tanto no âmbito da saúde pública como na saúde suplementar.

Em contrapartida, é preciso reconhecer que os magistrados não possuem conhecimento técnico que lhes permita avaliar se os pedidos apresentados são justificáveis ou não. O que fazem quase sempre é adotar a decisão indicada pelo médico que assiste o paciente e que, supostamente, está capacitado tecnicamente para recomendar a melhor solução médica para o caso. Se o médico indica um tratamento experimental com acurácia não comprovada, ou, se indica o uso de uma substância que não é medicamento homologado pelo órgão executivo federativo competente, mas que é apresentada como fator relevante para a melhora da saúde do paciente, o juiz não tem condições de aferir a veracidade da informação, porque raramente dispõe de acesso a um outro profissional médico que possa emitir um parecer sobre o assunto.

É importante considerar, ainda, que o médico atende o paciente de forma individualizada e com preocupações específicas para aquele caso concreto sem considerar valores ou custos decorrentes do tratamento, mas, apenas, as possibilidades de melhora ou de cura, ainda que remotas. O poder judiciário ao julgar o caso concreto recebe as informações técnicas de um médico que pretende que seu paciente receba o que há de melhor, ou seja, que receba o tratamento capaz de determinar mudanças positivas para seu estado de saúde, mesmo se este for um tratamento ou medicamento experimental ou de alto custo, ou ainda não devidamente comprovado por evidências científicas. 
A premissa que orienta a ação dos médicos é que tudo que não prejudique o paciente deve ser tentado para salvá-lo ou para alongar seu tempo de vida. O poder judiciário quando recebe o caso concreto para decidir está à mercê das premissas do médico, sem condições técnicas para avaliar o impacto que os tratamentos e medicamentos terão no custeio coletivo público ou privado.

O judiciário brasileiro carece de acesso a profissionais que possam subsidiá-los com dados técnicos para fundamentar decisões em situações em que o aspecto médico seja determinante para definir o substrato jurídico aplicável. São situações que para além dos argumentos subjetivos de proteção da dignidade da pessoa humana, ou, da garantia de acesso à saúde de modo integral e universal, necessitam de subsídios fáticos para fundamentar a decisão porque o alto custo de medicamentos e tratamentos incidirá, diretamente, sobre fundos mutuais, públicos ou privados, que estão sob a responsabilidade de gestão da administração pública ou privada, mas, cujo compromisso gerencial é com a sustentabilidade desses fundos para que não faltem recursos para outros usuários quando forem necessários.

As decisões judiciais a partir da opinião de um único médico são sempre um risco para os orçamentos públicos e para os fundos mutuais privados de saúde suplementar, porque podem não estar tecnicamente corretas ou isentas. Além disso, na atualidade, existem provas abundantes do desvio de função de médicos de área pública e privada que se renderam aos incentivos financeiros da indústria de próteses, órteses e materiais especiais, ou da indústria farmacêutica. ${ }^{\S}$ Todo esse quadro impõe mudança de posição em relação aos pedidos de medicamentos e tratamentos de alto custo.

3. Instrumentos de Análise Econômica do Direito na Solução de Conflitos por Mediação.

O fundamento teórico desta reflexão perpassa as bases da Análise Econômica do Direito (AED), em especial porque como Alvarez

A proposta do estudo interdisciplinar implica (a) rejeição da ideia de autonomia da própria ciência jurídica consoante a proposta do formalismo na reformulação de Langdell. Desta forma, retoma os postulados do realismo, isto é, a possibilidade do estudo científico da realidade jurídica desde o âmbito das ciência sociais, especificamente através da implicação da teoria econômica à análise e evolução da realidade legal. Implica também (b) erigir a perspectiva e a ciência econômica como referencial analítico da regulação e 
do sistema jurídico, com o que se abre o discurso jurídico à realidade social e se realiza a integração entre ciência econômica e ciência jurídica superando os limites do formalismo e estabelecendo um novo tipo de relação implicando: (i) que a interpretação e avaliação de uma norma realiza-se desde os pressupostos da teoria econômica; (ii) que a racionalidade de que se dota às normas e ao sistema jurídico em seu conjunto, é uma racionalidade do tipo econômico. Ainda, implica (c) colocar no centro dos estudos jurídicos os problemas relativos à eficiência do direito, ao custo dos instrumentos jurídicos na persecução de seus fins ou das consequências econômicas das intervenções jurídicas; bem como (d) tentativa de reconstrução do discurso através de uma linguagem tecnocrática: (i) porque os destinatários desse discurso não são tanto os indivíduos e/ou grupos, mas os operadores jurídicos que partem de uma visão funcional e operacional do direito; (ii) porque a utilização das técnicas de análise custo-benefício e a reformulação das categorias tradicionais em categorias econômicas levam a priorizar o caráter tecnocrático do discurso; e, (iii) porque o direito passa a ser compreendido como meio para atingir fins ou objetivo sociais, razão do instrumentalismo, resultando do movimento do realismo jurídico e do movimento do pragmatismo filosófico, bem como do movimento progressista. (ALVAREZ, A.B., 2006, p.51-52)

Em sentido semelhante Ivo T. Gico Jr. introduz o tema

O direito é, de uma perspectiva mais objetiva, a arte de regular o comportamento humano. A economia, por sua vez, é a ciência que estuda como o ser humano toma decisões e se comporta em um mundo de recursos escassos e suas consequências. A Análise Econômica do Direito, portanto, é o campo do conhecimento humano que tem por objetivo empregar os variados ferramentais e empíricos econômicos e das ciências afins para expandir a compreensão e o alcance do direito e aperfeiçoar o desenvolvimento e a avaliação das normas jurídicas, principalmente com relação às suas consequências. (GICO Jr. I.T. 2010, p.8)

Em nenhuma hipótese se pretende que a economia dite os fundamentos das decisões judiciais sobre saúde pública ou privada, seja no âmbito dos medicamentos de alto custo ou dos tratamentos de moléstias raras ou em qualquer outra dimensão da realidade. A utilização do ferramental da Análise Econômica do Direito nas questões que este trabalho analisa (medicamentos de alto custo e doenças raras), visa a busca de dados objetivos que permitam ao magistrado avaliar o impacto no orçamento público ou privado (operadoras de saúde), em razão das especificidades das duas situações analisadas.

Os fundamentos teóricos dos estudos de Análise Econômica de Direito permitem incluir a Medicina Baseada em Evidências como ferramenta por meio da qual se poderá avaliar a eficiência da utilização dos medicamentos e/ou tratamentos, para um determinado caso concreto levado ao poder judiciário para decisão de modo que essa decisão leve em conta: (a) a comprovação da necessidade de quem pede; (b) as evidências científicas 
sobre o resultado do tratamento e/ou medicamento; (c) os valores que serão dispendidos para que o tratamento e/ou medicamento seja custeado; (d) as consequências daquela decisão para os orçamentos públicos e fundos mutuais que custeiam os serviços de saúde pública e privada no Brasil e; (e) a possibilidade de mediação com fundamento em dados científicos que estimulem o paciente a encontrar meios paliativos de tratamento quando a cura estiver em percentual muito pequeno de possibilidade.

Com esses dados colocados objetivamente a hipótese de solução por mediação é viável, porque a própria parte que requer o tratamento e/ou medicamento poderá se convencer da ineficiência ou, do baixo índice de resultados positivos para situações semelhantes ou, ainda, de que o tratamento trará benefícios muito pequenos quando comparado com as consequências negativas para a qualidade de vida. Nesses casos, a mediação poderá contribuir para ampliar a visão do paciente e de seus familiares sobre outras possibilidades possíveis como, por exemplo, o tratamento paliativo.

Para agir no sentido de fornecer novas possibilidades para as pessoas às quais foi recomendado um tratamento e/ou medicamento de alto custo, por meio de mediação, a análise econômica do direito nos fornece pressupostos teóricos valiosos. Gico afirma

O método econômico se baseia em alguns postulados. Primeiro, os recursos da sociedade são escassos. Se os recursos não fossem escassos, não haveria problema econômico, pois todos poderiam satisfazer suas necessidades - fossem elas quais fossem. Curiosamente, a mesma ideia, com outra roupagem motivo o direito: se os recursos não fossem escassos, não haveria conflitos, sem conflitos, não haveria necessidade do direito, pois todos cooperariam ex moto próprio. A escassez dos bens impõe à sociedade que escolha entre alternativas possíveis e excludentes (senão não seria uma escolha, não é mesmo?)

Toda escolha pressupõe um custo, um trade off, que é exatamente a segunda alocação factível mais interessante para o recurso, mas que foi preterida. A esse custo chamamos de custo de oportunidade. (...) Note que dizer que algo tem um custo não implica afirmar que tem valor pecuniário. (...)

Como escolhas devem ser realizadas, os agentes econômicos ponderam os custos e os benefícios de cada alternativa, adotando a conduta que, dadas as suas condições e circunstâncias, lhes traz mais bem-estar. Dizemos, então, que a conduta dos agentes econômicos é racional maximizadora. (...)

A grande implicação desse postulado para a juseconomia é que se os agentes econômicos ponderam custos e benefícios na hora de decidir, então, uma alteração em sua estrutura de incentivos poderá leva-los a adotar outra conduta, a realizar outra escolha. Em resumo, pessoas respondem a incentivos. Ora, essa também é uma ideia central no direito. Todo 
direito é construído sobre a premissa implícita de que as pessoas responderão a incentivos. (...) (obra citada, p. 22)

Exatamente o que esta reflexão propõe, é incentivar aqueles para os quais foi recomendado um tratamento e/ou medicamento de alto custo, que considere os dados objetivos das evidências científicas e, na medida em que estes dados demonstrem que não se pode esperar um percentual elevado de bons resultados para a saúde após o uso dos recursos de alto custo, o paciente seja encaminhado para cuidados paliativos que poderão garantir qualidade durante o tempo de vida que restar, assim como um preparo psicológico efetivo, para o paciente e sua família, poderem vivenciar com serenidade a experiência final da vida.

A mediação poderá ser o instrumento de apresentação de alternativa ao tratamento e/ou medicamento de alto custo, construída com equipe de saúde multidisciplinar, em especial com psicólogos especializados nessa modalidade de atuação, cuidados paliativos, com objetivo de oferecer o melhor tratamento físico e psíquico diante de evidências que comprovem cientificamente que não se pode mais esperar cura para aquele caso concreto.

4.Medicina Baseada em Evidências e sua Aplicação na Mediação de Conflitos de Saúde.

A hipótese de que a mediação possa ser utilizada em situações judicializadas em que o paciente/requerente recebeu a recomendação médica de realizar tratamento e/ou utilizar medicamento de alto custo, negada pelo Sistema Único de Saúde ou por alguma operadora de saúde, encontra fundamento jurídico em estudos de análise econômica do direito, conforme demonstrado no item anterior e, fundamentos técnicos nos estudos de medicina baseada em evidências.

Medicina baseada em evidência é a busca da melhor evidência científica para o caso concreto aliada à experiência clínica do médico e, aos desejos do paciente.

Evidência, como define Clark, é a pesquisa clinicamente relevante, especialmente aquelas centradas em pacientes, e que prezam pela acurácia e precisão de testes diagnósticos, o poder de marcadores prognósticos e a eficácia e segurança de procedimentos terapêuticos e preventivos. (CLARK, 2009, p. 28)

Após definido o tratamento que o médico do paciente pretende realizar, por exemplo, uma nova tecnologia cirúrgica ou um novo medicamento, o profissional especializado em medicina baseada em evidências realiza pesquisa sistemática em bancos de dados nacionais e 
internacionais dos mais referenciados institutos de pesquisa e universidades, referentes à utilização daquela técnica ou medicamento em casos assemelhados e, quais resultados foram obtidos e relatados em artigos científicos.

Depois disso, o profissional médico especializado em medicina baseada em evidência sistematiza os dados obtidos e efetua a comparação com os protocolos e políticas de saúde utilizadas em vários organismos mundiais, para comparar o caso pesquisado com casos semelhantes.

Ao final, é possível concluir se existem ou não evidências científicas para a realização daquele tratamento ou para o uso do medicamento indicado e, se ele é, realmente, o mais indicado para o quadro de saúde do paciente ou, se não é indicado e por qual razão não é.

A medicina baseada em evidências reúne um conjunto de informações científicas com qualidade reconhecida pela comunidade científica nacional e internacional, para avaliar se a utilização de uma tecnologia ou um medicamento tem ou, não tem, fundamentação científica suficiente que autorize o custo que vai ser dispendido pelo fundo mutual público ou privado.

Nas doenças graves ou raras é comum que, uma vez esgotado o tratamento previsto no protocolo, o médico continue tentando a cura ou a redução dos efeitos da doença com a utilização de tecnologias ou medicamentos não indicados para aquele diagnóstico, mas que, no entanto, hipoteticamente poderão produzir algum resultado benéfico. Todos têm direito de procurar a cura de seus males até o final da vida, porém quando se trata da utilização de recursos coletivos públicos ou privados mutuais, é necessário que essa utilização seja revestida de fundamentos científicos que comprovem a possibilidade de melhora ou de cura, sob pena de serem utilizados inutilmente os valores obtidos com a contribuição da coletividade pública ou privada.

O que a medicina baseada em evidência permite é a comparação da recomendação médica baseada em experiência clínica com os estudos científicos mais avançados e atualizados disponíveis, permitindo que os médicos avancem com segurança quando o tratamento recomendado estiver respaldado em estudos científicos ou, recuem em tempo de 
evitar prejuízos maiores quando o tratamento recomendado não estiver amparado por estudos científicos que comprovem sua eficácia.

O uso do método da medicina baseada em evidência contribui para suprir a defasagem da experiência clínica do médico que, muitas vezes, apesar de especialista e experiente em determinada área da medicina, nem sempre possui condições de estar em dia com os avanços da pesquisa científica realizada no Brasil e no mundo e, nem sempre atuou em quantidade de casos suficientes para coletar dados que lhe permitam tomar decisões eficientes.

Assim, para casos de alta complexidade e alto custo o estudo sistematizado realizado por profissionais especializados em medicina baseada em evidência é recomendado para que seja realizada análise científica, que compare o tratamento/medicamento recomendado com experiências realizadas nos principais centros de pesquisa do país e do mundo e que, ao final, aponte o resultado da comparação para determinar se existem possibilidades de êxito na aplicação do tratamento ou medicamento indicado e, qual o percentual dessa possibilidade.

É garantia constitucional de que todos devem lutar pela vida com qualidade e dignidade. Ninguém pode ser impedido de utilizar tudo o quanto considera necessário para seu tratamento de saúde, na busca dos melhores resultados. Porém quando se trata da utilização de recursos coletivos públicos ou privados, as melhores práticas de gestão recomendam gerenciar a escassez e, para isso, é positivo que sejam realizados estudos prévios de viabilidade e eficácia, de forma objetiva e racional, para preservar a sustentabilidade dos fundos para os quais contribuíram milhões de pessoas com seus recursos pessoais, seja pelo pagamento de tributos para sustento da saúde pública, seja com o pagamento de mensalidades para a saúde privada.

5. Núcleos de Conciliação para Tratamentos e Medicamentos de Alto Custo

Mediação, segundo o parágrafo segundo da Lei 13.140, de 26 de junho de 2015, é a atividade técnica exercida por um terceiro imparcial sem poder decisório que, escolhido ou aceito pelas partes, as auxilia e estimula a identificar ou desenvolver soluções consensuais para controvérsias.

É um mecanismo dinâmico por meio do qual o mediado estimula e auxilia as partes a refletirem sobre o conflito, sobre as diferenças de argumentos e sobre as possibilidades de 
encontrarem pontos comuns que as levem a uma solução construída, resultado da atuação das partes em conflito e por elas assumida como a solução mais eficaz.

O novo Código de Processo Civil brasileiro, Lei 13.105, de 2015, adotou a mediação e a conciliação como instrumentos legais para a solução de controvérsias judiciais. No artigo $2^{\circ}$ do texto legal, está determinado que o Estado promoverá, sempre que possível, a solução consensual do conflito e que a conciliação, a mediação e outros métodos de solução consensual de conflitos deverão ser estimulados por juízes, advogados, defensores públicos e membros do Ministério Público, inclusive no curso do processo judicial. O artigo 139 do novo Código de Processo Civil determina que o juiz dirigirá o processo conforme o previsto na lei e que lhe incumbirá promover a qualquer tempo a auto composição, preferencialmente com o auxílio de conciliadores e mediadores judiciais.

Assim, tanto em fase prévia do ajuizamento da ação como após o ajuizamento, é permitido ao juiz e às partes proporem a mediação ou a conciliação como mecanismo de solução de conflitos.

No caso específico de tratamentos e medicamentos alto custo a mediação poderá ser praticada por núcleos de conciliação que contém com o trabalho de profissionais especializados em medicina baseada em evidência. Sempre que o paciente cujo médico tenham recomendado um tratamento ou medicamento de alto custo se dirigir ao poder judiciário para pleitear uma decisão individual, será estimulado a passar por pelo menos uma sessão de mediação juntamente com o representante do poder público ou da operadora de saúde privada que tenha negado o custeio do tratamento ou medicamento. Nessa sessão de mediação, o mediador efetivará os esforços necessários para que o conflito fique definido de forma objetiva e, as partes aceitem submeter o caso ao resultado da pesquisa científica que será efetuada pelos profissionais de medicina baseada em evidências.

Em seguida à sessão se houver acordo entre as partes, os exames clínicos e relatório médico do paciente serão comparados com evidências científicas de bancos de dados especializados, com o objetivo de identificar objetivamente se o tratamento ou medicamento recomendado tem sustentação científica em estudos realizados e publicados em revistas e jornais científicos de comprovada credibilidade e qualidade. 
Caso os resultados da pesquisa e da comparação indiquem que o tratamento/medicamento recomendado pelo médico é o mais adequado, com sustentação científica para ser aplicado àquele caso concreto, as partes deverão compor a forma pela qual ele será custeado, inclusive, se necessário, com eventual coparticipação do paciente e de sua família caso não existam recursos públicos ou privados para sustentarem o custeio.

Nos casos em que o resultado da pesquisa e da comparação realizada por médicos especialistas em medicina baseada em evidência apontar que não existem indicativos de acurácia ou de melhoria do paciente em decorrência do tratamento, então o paciente e seu médico deverão concordar que o custeio não será feito pelo poder público ou pelos recursos particulares, embora possa ser feito diretamente pelo paciente e seus familiares caso existam possibilidades econômicas.

Em nenhuma hipótese o resultado da pesquisa realizada pelos profissionais especializados em medicina baseada em evidências será uma decisão definitiva para ser imposta às partes, mas seus elementos técnicos serão utilizados como elucidação no mecanismo de mediação e, caso não haja solução conciliatória poderão ser utilizados pelo magistrado da causa para fundamentar sua decisão.

A conciliação com a utilização de argumentos técnicos e científicos de ótima qualidade, poderá contribuir para que pacientes e médicos assistentes compreendam que, muitas vezes, as novas tecnologias não são melhores apenas por serem mais recentes; que os medicamentos experimentais ou off label (utilizados para finalidades distintas daquelas para as quais foram criados), não são a solução que garantirá acurácia ou melhora do estado do paciente. Esses medicamentos poderão, por vezes, prolongar por algum tempo a perspectiva de sobrevida, porém sem qualidade de vida e sem garantia de que resultarão em cura ou em melhora efetiva.

Todos esses aspectos serão objeto de diálogo entre as partes na mediação, porém alicerçados em dados científicos capazes de diminuir a influência dos argumentos subjetivos e excessos emocionais que são compreensíveis, porém não criam resultados práticos de maior significância.

A utilização de medicina baseada em evidência para fornecer dados científicos para casos de alta complexidade e/ou alto custo de tratamento, poderá ser realizada a partir de 
convênios com instituições públicas e privadas que realizam estudos e pesquisas em área da saúde, como faculdades, universidades, centros e institutos de pesquisa.

Para as universidades, faculdades e institutos de pesquisa de caráter público atuar em parceria com o poder judiciário é obrigação, porque elas são custeadas com recursos de contribuintes. Para as instituições privadas que quiserem realizar convênio com o poder judiciário poderá ser criada uma forma de redução ou isenção fiscal de tributos incidentes sobre suas atividades, durante o período em que vigorar o convênio com o poder judiciário.

Os núcleos de mediação com utilização de medicina baseada em evidência e atuação de equipe de saúde multidisciplinar, poderão indicar aos pacientes, em alguns casos, os cuidados paliativos como melhor forma de tratamento, quando os dados científicos apontarem que aquele caso não tem previsibilidade de cura ou de melhora significativa.

Cuidados paliativos, segundo a OMS consistem na assistência, promovida por uma equipe multidisciplinar, que objetiva a melhoria da qualidade de vida do paciente e de seus familiares diante de uma doença que ameace a vida, por meio da prevenção e do alívio do sofrimento da identificação precoce, avaliação impecável e tratamento de dor e demais sintomas físicos, sociais, psicológicos e espirituais.

\section{Ensina Ana Claudia Quintana Arantes}

Os cuidados paliativos podem ser úteis em qualquer fase da doença, mas sua necessidade e seu valor ficam muito mais claros quando a progressão atinge níveis elevados de sofrimento físico e a medicina nada mais tem a oferecer.

$(\ldots)$

Penso que todo o médico deveria ser preparado para nunca abandonar seu paciente, mas na faculdade aprendemos apenas a não abandonar a doença dele. Quando não há mais tratamentos para a doença, é como se não tivéssemos mais condições de estar ao lado do paciente. (....) O médico que foi treinado sob o conceito ilusório de ter poder sobre a morte está condenado a se sentir fracassado em vários momentos da carreira. (ARANTES, A.C. Q. 2016, p. 46-47)

No Brasil, como não há preparo adequado dos médicos para os cuidados paliativos em casos para os quais não existam mais recursos terapêuticos comprovados, é comum que os médicos continuem insistindo em ministrar medicamentos ou tratamentos para os quais não se pode garantir resultado, mas que simbolizam apenas a "não desistência da luta pela vida do paciente”, o que embora tenha fundamentos nobres tem, também, péssimos resultados para a 
sustentabilidade dos sistemas público e privado além de enorme desgaste para o doente e seus familiares.

Mediar a partir de dados científicos para garantir tratamentos e/medicamentos de alto custo apenas com chance de cura e, para indicar tratamento paliativo para os demais casos, sem chance de cura, é racionalizar a gestão de recursos e efetivar o melhor conceito de justiça no caso concreto.

\section{Conclusão}

Com assiduidade chegam aos tribunais brasileiros demandas judiciais para pleitear medicamentos e/ou tratamentos de alto custo que serão suportados por recursos econômicos públicos ou privados. Esses pedidos são embasados em recomendações médicas que nem sempre são acompanhadas de fundamentação científica objetiva, capaz de comprovar que aquele tratamento ou medicamento será capaz de promover melhoras no estado de saúde, ou, prolongar com qualidade a sobrevida do paciente.

Todos têm direito à vida e à saúde em conformidade com o que determina a Constituição Federal brasileira, porém, quando se trata da utilização de recursos públicos ou privados para os quais contribuíram muitas pessoas, seja por recolhimento de tributo ou por pagamento direto em decorrência da existência de contrato privado, os direitos não são absolutos e sim relativos, justamente porque envolvem a mutualidade.

As decisões quase sempre são deixadas para o convencimento do magistrado que à míngua de outros recursos técnicos, opta por deferir o pedido fundamentado em relatório médico do assistente do paciente, sem discutir por total falta de elementos objetivos a qualificação do médico que prescreveu o tratamento ou medicamento de alto custo.

Este trabalho propõe que os magistrados sejam auxiliados por núcleos de mediação que, além de um mediador preparado para o exercício técnico de sua função, também utilizarão as técnicas de medicina baseada em evidências para avaliar se o tratamento e/ou medicamento indicado é, realmente, utilizado com bases científicas comprovadas para a doença diagnosticada no paciente.

Os médicos com especialidade em medicina baseada em evidencia serão captados em universidades, faculdades e institutos de pesquisa, públicos ou privados, com os quais os tribunais de justiça ou, o Conselho Nacional de Justiça, firmará convênios. 
Para as universidades, faculdades e institutos de pesquisa o convênio é benéfico porque permite realizar pesquisas a partir de estudos de casos concretos, de forma a permitir ampliar o universo de conhecimento, de variáveis a serem consideradas e de estudos a serem realizados. Para os gestores de saúde pública e privada os grupos de pesquisa em medicina baseada em evidência atuando junto a núcleos de mediação são positivos porque permitirão melhor gestão dos recursos mutuais, com segurança de que os resultados são cientificamente apontados como os mais acertados.

Para os magistrados que têm a incumbência de julgar assunto técnico para o qual não se encontram preparados e nem poderiam estar, porque são parte do conhecimento de outra área do saber, os relatórios dos grupos de pesquisa de medicina baseada em evidência serão fundamento técnico de grande valor para a construção de seu convencimento, aliado a outras provas produzidas nos autos.

Para os mediadores a existência de dados científicos permitirá trabalhar com as partes envolvidas na mediação de forma mais objetiva, para conseguir equilibrar argumentos emocionais e racionais com maior efetividade, sempre em benefício do cidadão paciente que precisa compreender suas possibilidades e, por vezes, ser informado que não existem técnicas seguras que possam lhe garantir a continuidade da vida. Para essas situações em que a medicina não puder mais oferecer recursos comprovados, tentativas infundadas e de alto custo poderão ser substituídas por cuidados paliativos, recomendados e orientados por profissionais especializados, que garantirão dignidade da pessoa humana.

Por fim, para toda a sociedade o uso de mecanismos mais racionais para a decisão de utilização de recursos de fundos mutuais, públicos ou privados, é a segurança de que a gestão está sendo realizada com responsabilidade, compromisso com a melhor qualidade de informação e de obtenção de dados e, em especial, com exemplar respeito à dignidade humana.

\section{Referências Bibliográficas}

ALVAREZ, Alejandro Bugallo. Análise Econômica do Direito: Contribuições e Desmistificações. Direito, Estado e Sociedade - v. 9 - n. 29 - p. 49-68 - jul/dez 2006. 
BECK, Ulrich. Sociedade de Risco. S.Paulo: 34, 2017.

ARANTES, Ana Cláudia Quintana. A Morte é Um Dia que Vale a Pena Viver. R. de Janeiro: Casa da Palavra, 2016.

CLARK, Otávio. Medicina Baseada em Evidências para Auditores. In GONÇALVES, Viviane Fialho (organizadora) Fronteiras de Autoria em Saúde. São Paulo: Farol do Forte, 2009.

GICO JR. Ivo T., Metodologia e Epistemologia da Análise Econômica do Direito. In Economic Analysis of Law Review. Volume 1, p. 7-33, Jan-Jun, 2010.

MORIN, Edgar. Os Sete Saberes Necessários para a Educação do Futuro. S.Paulo: Cortez, 1999.

STARCK, Christin. Dignidade Humana como Garantia Constitucional: o exemplo da Lei Fundamental Alemã. Tradução Rita Dostal Zanini in SARLET, Ingo W. (organizador) Dimensões da Dignidade. Ensaios de Filosofia do Direito e Direito Constitucional. $2^{\mathrm{a}}$ edição. $2^{\mathrm{a}}$ Tiragem. Porto Alegre: Livraria do Advogado, 2013.

SEGRE, Marco; FERRAZ, Flávio Carvalho. O conceito de saúde. Rev. Saúde Pública, São Paulo , v. 31, n. 5, p. 538-542, Oct. 1997 . Available from $<$ http://www.scielo.br/scielo.php?script=sci_arttext\&pid=S0034-

89101997000600016\&lng=en\&nrm=iso>. access on 28 Mar. 2018. http://dx.doi.org/10.1590/S0034-89101997000600016. 